Running Head: THE MARKET FOR IDEOLOGY

\title{
The Market for Belief Systems: A Formal Model of Ideological Choice
}

\author{
Thomas Gries and Veronika Müller \\ University of Paderborn \\ Department of Economics \\ 100 Warburger Strasse, 33098 Paderborn, Germany \\ thomas.gries@uni-paderborn.de \\ muellerv@campus.uni-paderborn.de
}

John T. Jost

New York University

Departments of Psychology and Politics

6 Washington Place, 5th Floor, New York, NY 10003 USA

john.jost@nyu.edu

Acknowledgements: This paper will be presented at the annual meeting of the American Political Science Association (September 10, 2020). A much earlier version was presented under the auspices of the Center for Social and Political Behavior at New York University. We are especially grateful for helpful comments we received on that occasion from Andrew Caplin, Eric Dickson, and Yaacov Trope. 


\begin{abstract}
Belief systems play a crucial role when it comes to guiding human information processing, evaluation, judgement, behavior, and social coordination. But why do individuals and groups adopt the specific ideologies they do? And is it possible to use the tools of economics to understand the decisions that are made in the market for ideology? To address these and related questions, we synthesize insights garnered from standard rational choice models, characteristics demand theory, and the distance theory of voting, as well as theory and research on "elective affinities" in psychology. We offer a formal analysis of the role of psychological and consumption needs in shaping the individual's choice of ideology under circumstances of uncertainty and limited resources and other constraints, including informational costs associated with learning about the potential match values of specific ideologies. After providing a few examples, we mention one non-obvious implication of our model, namely that people can be "wrong" about their own ideological preferences according to the criteria of rational consistency and utility maximization.
\end{abstract}


If you wish to strive for peace of soul and happiness, then believe; if you wish to be a disciple of truth, then inquire. (Friedrich Nietzsche, letter to his sister)

Socially shared beliefs, including political and religious systems of thought, play a meaningful, if not decisive, role in the lives of most individuals (Jost, 2006). According to the Pew Research Center, three-fourths of Americans endorse some religious creed, and $45 \%$ report relying on those beliefs to make major life decisions (Pew, 2016). More than half of the believers worry that their belief systems are losing influence in America, and roughly $40 \%$ perceive conflict between their own beliefs and mainstream culture (Pew, 2020a). Even atheists and agnostics may hold "New Age" beliefs - including beliefs in astrology, reincarnation, spiritual energy, and psychic phenomena (Pew, 2018).

With respect to politics, ideological worldviews affect voting behavior and other forms of participation (Jost, in press). In recent years, for example, they have inspired millions around the globe to join demonstrations on the left in support of the natural environment and against institutionalized racism — as well as demonstrations on the right against immigrants and Muslims. All over the world, many subscribe to conspiracy theories, such as the belief that "the coronavirus outbreak was intentionally planned by powerful people" (Pew, 2020b).

According to Ernest Gellner (1959), ideology "manifests itself simultaneously as a set of ideas or doctrines, a set of practices, and a more or less closely organized, more or less institutionalized social group. The ideas form a reasonably connected system, related in part by mutual entailment such that if key ideas are understood, the others follow" (pp. 231-232). An ideology, then, is a network of attitudes and beliefs, the elements of which are linked together logically and/or psychologically (McGuire, 1999; Sniderman, Brody, \& Tetlock, 1991). Political and religious ideologies include descriptive beliefs about the way the world is as well as 
normative or prescriptive beliefs about the way it should be (Jost, 2006).

There are two major schools of thought when it comes to the social scientific study of ideology, and at first blush it is unclear how they could ever be reconciled. According to some theorists, including Graham Wallas (1908) and Harold Lasswell (1930), the belief systems of leaders and their followers are often shaped by dark, destructive, and irrational forces, such as intense passions and prejudices. Adorno, Frenkel-Brunswik, Levinson, and Sanford (1950) also emphasized the irrational dimension of mass ideology in their monumental analysis of The Authoritarian Personality. Inspired by the Frankfurt School, these authors combined Freudian theorizing about psychological defenses such as denial, repression, rationalization, and projection with Marxian theorizing about the ideological legitimation of social and economic exploitation, with the goal of explaining the popular appeal of fascism in Europe and the U.S. (McGuire, 1999). The irrational hatred that motivates anti-Semitism and anti-Black racism was probed further by Bettelheim and Janowitz (1964), who registered "a tendency, among the intolerant, to select the Jew for projecting onto him those tendencies rejected by the superego (for instance, the individual's desire to take advantage of others), while id desires were projected onto the Negro" (p. 147).

Although the influence of psychoanalysis long ago waned in scientific psychology, the idea that non-rational motives drive political and religious ideologies has not (Jost, Glaser, Kruglanski, \& Sulloway, 2003). Research suggests, for example, that exaggerated perceptions of danger and threat contribute to the development of an authoritarian worldview, whereas preoccupations with competition contribute to worldviews emphasizing social dominance (Altemeyer, 1998; Duckitt, 2001; Sidanius \& Pratto, 2001). Other studies suggest that unresolved emotional conflicts - especially when it comes to fear, anger, and shame - play a role in certain 
political and religious belief systems, including right-wing extremism, populism, and religious fundamentalism (Jost, 2019; Milburn \& Conrad, 1996; Salmela \& von Scheve, 2017). ${ }^{1}$

A very different school of thought, typically associated with the discipline of economics, treats ideological preferences as the product of rational decision-making under circumstances of uncertainty (Denzau \& North, 2000; Hinich \& Munger, 1994). In the realm of politics, for instance, ideologies are regarded as energy-saving devices that "remove the necessity of [the individual] relating every issue to his [or her] own philosophy"; "focus attention on the differences between [political] parties"; and "save... the cost of being informed upon a wider range of issues" (Downs, 1957, p. 98). A major assumption is that voters rely on ideological schemas as heuristic cues (Hamill, Lodge, \& Blake, 1985) that help them to reduce subjective uncertainty about whether policies enacted by certain political candidates or parties will be harmful or beneficial for them (Hinich \& Munger, 1994). Gathering enough information to obtain a complete understanding of the implications of a given political decision or outcome is effortful and costly. Relying on belief systems helps to solve this information problem; they free the individual up from needing to accurately evaluate incoming information and from various problems of communication and social coordination.

From the perspective of rational choice, one fairly obvious basis for ideological preferences is economic self-interest. All other things being equal, rich people should prefer lower tax rates and less public investment in social welfare provisions than poor people. Likewise, members of underprivileged racial minority groups should be more supportive of policies that prevent racial discrimination in housing, education, and job markets, and instead

\footnotetext{
${ }^{1}$ We are not suggesting that emotional influences on ideology are necessarily irrational, only that some are, such as the projection of repressed anger onto scapegoats (Allport, 1954).
} 
promote equal rights and opportunities, in comparison with members of privileged majority groups (Weeden \& Kurzban, 2015). This is not to suggest that the only rational basis for ideological preferences is selfishness. On the contrary, cooperative and other-regarding preferences may very well be deemed rational (Fehr \& Schmidt, 1999), especially when viewed at a collective level of analysis, as noted above. The important point is that, as Hinich and Munger (1994) put it, "Ideology is not nonrational, it is not a residual or random component of conscious human decision making" (pp. 236-237). Furthermore, according to this view, socially shared belief systems are indispensable when it comes to communication and coordination; they make it possible for "large societies... to act like communities" (p. 235).

Although rational and irrational accounts of ideologies may appear to be incommensurable, they are not. In this article we develop a formal model of choice that conceptualizes ideological outcomes as arising jointly from (a) the individual's expected utility that comes from satisfying a specific set of needs, interests, and motives that are tied to various ideological positions, and (b) the ideological "offers" or opportunities for reconciliation that are available in the socially shared informational environment. There are, in other words, buyers and sellers in the market for ideology. Whether the decisions made by these two parties are to be considered rational or irrational is a complex matter that can only be decided on a case-by-case basis, much as some purchases (and sales) are made in accordance with principles of rationality while others may not be. There are also potential conflicts between individual and collective rationality. For instance, an ideological preference that is rational for the individual to hold, such as a philosophy based on greed, may be irrational when it is adopted by many people in society, as in the case of the commons dilemma (Hardin, 1968).

The important point is that all ideological outcomes - whether or not they are 
normatively defensible in terms of standards of morality or rationality - may be understood as the result of a decision-making process under circumstance of uncertainty and limited resources. This process need not be a conscious or deliberate one; it may be the result of either System 1 or System 2 thinking, or some combination of intuitive and analytic processes (Kahneman, 2011). Importantly, the process (a) is constrained by dispositional and situational factors that are internal and external to the individual, consistent with an "elective affinities" model of ideological preferences (Jost, Federico, \& Napier, 2009), and (b) can be formally represented in terms of a multi-dimensional measure of ideological distance, as in rational choice models of political decision-making (Hinich \& Munger, 1994).

A model like this one is sufficiently general so as to incorporate determinants of subjective utility that are considered to be rational, such as economic self-interest, as well as those that are considered to be irrational, such as unwarranted hatred and prejudice. For most individuals, we expect that their ideological preferences reflect a mix of rational and non-rational considerations or, as Bénabou and Tirole (2016) put it, an implicit trade-off between accuracy and desirability. There can be little doubt that some ideologies embrace "a great absurdity, a violent intellectual resistance-generating offensiveness" (Gellner, 1959, p. 233), but this does not mean that it is impossible to explain their appeal in scientific terms. On the contrary, what is needed is a general theoretical framework that can account for the existence of a wide variety, though not an infinite variety, of ideological forms (see also Khalil, 2011).

\section{The Demand Side: Psychological Determinants of Subjective Utility}

What are the needs, interests, and motives that shape the demand for ideology? As noted above, considerations of economic self-interest, as in cases of "pocketbook" voting and desires for the consumption of goods and services surely play a role in some ideological preferences. 
The same is true of group interests - which may take material forms such as perceptions of resource competition (Bobo \& Hutchings, 1996) or symbolic forms associated with "identity politics" (Jardina, 2019; Mason, 2018). In addition to these factors, Jost, Federico, and Napier (2009) proposed that epistemic, existential, and relational needs to reduce uncertainty, threat, and social discord help to explain why people are drawn to socially shared belief systems in general and why specific ideologies — such as politically conservative ideologies that emphasize the maintenance of tradition and legitimation of familiar forms of hierarchy and inequality — may be especially appealing to certain individuals and groups.

In terms of epistemic motives, the following psychological variables are known to predict left-right ideological preferences: cognitive and perceptual rigidity; intolerance of ambiguity; uncertainty avoidance; dogmatism; personal needs for order, structure, and closure; need for cognition; cognitive reflection; integrative complexity (Jost, Sterling, \& Stern, 2018a). In terms of existential motives, subjective perceptions of threat and exposure to objectively threatening circumstances — such as terrorist attacks, pandemic diseases, and seismic shifts in racial demography — are associated with more conservative (and less liberal) preferences (Jost, Stern, Rule, \& Sterling, 2017). In terms of relational motives, ideological outcomes are linked to individual differences in desires for conformity, group homogeneity, and the attainment of a shared sense of reality with like-minded others (Jost, van der Linden, Panagopoulos, \& Hardin, 2018b). Presumably there are many other psychological needs and interests that make certain ideologies more or less appealing to a given individual.

For instance, Gries and Müller (2020) propose that a variety of prosocial needs — such as empathy, altruism, and caring for others — are likely to affect the individual's choice of ideology. They also highlight needs for self-esteem, self-efficacy, and self-determination, all of which may 
contribute to ideological preferences. Some of the foregoing are at least partially overlapping with the three needs that Deci and Ryan (2000) regarded as psychologically fundamental and culturally universal, namely autonomy, competence, and relatedness. There are also earlier taxonomies, such as Maslow's (1943) hierarchy, which specified physiological needs for food, water, and oxygen; needs for physical safety and a sense of security; needs for love and acceptance; needs for positive self-esteem; and needs for self-fulfillment or self-actualization (Pittman \& Zeigler, 2007). McClelland (1961) identified three needs as being especially important to human functioning, namely needs for achievement, affiliation, and power.

Murray (1938) enumerated 28 specific needs, but these can be organized in terms of 7 major categories: ambition, information exchange, interpersonal affection, material possessions, power, and status in the eyes of others. Rokeach (1973) introduced a distinction between instrumental and terminal values. Examples of instrumental values, which have to do with “desirable modes of conduct," include being ambitious, broadminded, capable, cheerful, clean, courageous, forgiving, helpful, honest, imaginative, independent, intellectual, logical, loving, obedient, polite, responsible, and self-controlled. Examples of terminal values, which pertain to “desirable end-states of existence," include the attainment of a comfortable life, an exciting life, a sense of accomplishment, a world at peace, a world of beauty, equality, family security, freedom, happiness, inner harmony, mature love, national security, pleasure, salvation, selfrespect, social recognition, true friendship, and wisdom. Rokeach linked many of these values to specific ideological preferences for liberalism, conservatism, socialism, and fascism (see Jost, Basevich, Dickson, \& Noorbaloochi, 2016, for a review).

The point is that there is a potentially very large number of psychological needs, interests, and motives that people wish to satisfy, and the extent to which specific ideological options are 
expected to satisfy them is a major determinant of subjective utility. This creates opportunities for ideological entrepreneurs, such as political or religious leaders, to make offers that are psychologically appealing on multiple grounds. In Table 1 we have attempted to list (nonredundantly but also non-comprehensively) the yield of needs, interests, and values from various psychological taxonomies in order to convey something about the quantity and quality of possible bases of ideological competition. It follows that ideological offers that are expected to satisfy multiple needs - and especially those needs that are viewed by the individual as highly important — will be more desirable (and therefore more likely to be accepted) than offers that address a smaller number of less important needs.

Matters are made even more complicated by the fact that the salience and intensity of psychological needs varies situationally as well as dispositionally (e.g., Jost et al., 2003, 2009, 2017, 2018a). Ultimately, what is needed is a model of the market for ideology that takes into account not only shifting consumer demand but also variability in the informational environment or supply (Federico \& Malka, 2018). Although the psychological model we present in this article focuses on the demand side of the market for idology, it may be useful to make a few more observations about the supply side. 


\section{Epistemic Needs}

Certainty; predictability; control; cognitive and perceptual consistency; uncertainty reduction; avoidance of ambiguity; order, structure, and cognitive closure; belief confidence; need for cognition (enjoyment of thinking); curiosity; excitement; cognitive reflection; epistemic accuracy; integrative complexity; wisdom (e.g., Festinger, 1954, 1957; Jost et al., 2018a; Kruglanski, 2013; Ruisch \& Stern, 2020; Toner et al., 2013; Rokeach, 1973; Thompson et al., 1994; Trope, 1979)

\section{Existential Needs}

Physical safety; security; comfort; risk assessment; perceptual vigilance; threat reduction; fear management; self-esteem; autonomy; personal freedom; self-determination; achievement; competence; self-efficacy; denial of death anxiety; sexual gratification; terror management (e.g., Becker, 1973; Berger \& Luckmann, 1966; Deci \& Ryan, 2000; Jost et al., 2017; Maslow, 1943; Pittman \& Zeigler, 2007)

\section{Relational Needs}

Affiliation; conformity; relatedness; social belongingness; empathy; care; altruism; interpersonal affection; friendship; love; acceptance; cooperation; group coordination; social status; power; information exchange; desire to share a sense of reality with like-minded others

(e.g., Baumeister \& Leary; Hardin \& Higgins, 1995; Jost et al., 2018b; McClelland, 1961; Murray, 1938; Tafel \& Turner, 1986)

Table 1: Psychological needs on which individuals differ and that may be well-served by ideological offers: A non-exhaustive list based on theory and research

\section{The Supply Side: Ideological Opportunities for Need Reconciliation}

To the extent that one's society provides the individual with an ideological "menu"

(Sniderman \& Bullock, 2004) — a reasonably wide range or variety of legitimate belief systems to choose from, as in a prototypical democratic political system-he or she is in a position to select reconciliation options that match his or her psychological needs and material interests. The choice of a belief system therefore takes place in what might be thought of as "the market for ideologies," a virtual space in which individuals and groups seek to satisfy their own ideological demands by selecting an option that is made available on the supply side. In this way, every 
ideological outcome (or reconciliation) is the irreducible product of an interaction between "sellers" and "buyers." The notion that some correspondences between psychological and ideological forms are "menu-independent," as argued by Malka and Soto (2015), is incoherent, from our perspective. It makes approximately as much sense as the notion that some purchases involve a buyer but no seller.

The idea that people gravitate toward certain ideologies in an attempt—not necessarily conscious or rational - to satisfy their own needs should not be taken to mean that those needs are fixed or stable. On the contrary, many consumer tastes, preferences, and values are personally and socially constructed and may be created or elicited through ongoing interaction (Ariely, Loewenstein, \& Prelec, 2006; Slovic, 1995). This means that the market for ideology can be manipulated or exploited for political (or economic) gain. According to Brock and RabinHavt (2012) in their book The Fox Effect: How Roger Ailes Turned a Network into a Propaganda Machine, this is what has transpired with the Fox News Channel over the past two decades or more.

Our conception of the market for ideology builds on and extends the theory of political ideology as motivated social cognition (Jost et al., 2003a, 2003b), which posited that individuals embrace belief systems that address their underlying needs and desires, as well as the "elective affinities" model of political ideology (Jost et al., 2009), which posited an interaction between "top-down" influences of elite communication and cultural socialization, on one hand, and "bottom-up" influences, such as psychological and physiological dispositions of the individual. One key assumption, which was inherent in the work of Silvan Tomkins (1995), is that individuals are attracted to either the left or right ideological pole on the basis of underlying needs, goals, and interests, but they are only capable of expressing that attraction to the extent 
that they are exposed to a reasonably wide range (or menu) of options (see also Jost, in press).

In this article we extend and formalize the general "elective affinities" approach in two main ways. First, we consider the appeal of a much broader set of belief systems, including nativist, populist, religious, and racial ideologies that may or may not be located easily in leftright ideological space (e.g., see Vincent, 2010). Among other things, the metaphor of a market for ideology highlights the role of ideological entrepreneurs who may configure belief systems in novel ways to address - and, indeed, create - shifts in consumer demand. Second, we develop some of the implications of a formal mathematical model of ideological choice that, as noted above, takes into account both rational and irrational calculations of subjective utility. Our assumption is not that individuals and groups perform mathematical calculations in order to determine the ideology that is "best" for them, but rather than they engage in a process of trialand-error that, over time, leads them to converge on a particular belief system that is on offer in their informational environment and that reasonably satisfies — or, in some cases, may even maximize - considerations of subjective utility.

The result of this decision-making process is an ideological outcome that provides a good "fit" when it comes to matching the individual's social, cognitive, and motivational orientations (e.g., Higgins, 2000). It is as if the individual has solved a rational choice equation to make his or her ideological selection, based upon expectations of satisfying psychological and other needs, whether or not the selection is ultimately deemed to be rational. As noted above, it is a complicated question as to whether the basis for a given ideological preference is to be considered rational or irrational, and what may seem to be rational at the individual level may be irrational at the collective level (and vice versa). What we propose is simply that different belief systems are presented as options or offers of reconciliation in a marketplace of ideas and that 
individuals are inclined to accept or reject them as a function of their own needs and interests.

\section{A Formal Model of Ideological Choice}

In this section, we use the tools of economics to understand broadly why people choose certain belief systems (over others) and adhere to them. In particular, we apply a standard rational choice model to describe an individual's selection of an ideology that satisfies his or her psychological demands under various constraints. Our decision-making model will also incorporate material consumption needs with the aim of providing a more comprehensive picture of individual behavior.

As mentioned previously, we begin by assuming that every individual possesses certain psychological and physiological characteristics as well as a multidimensional set of needs, interests, and concerns arising from these. Additionally, we take it that people will seek to reconcile these needs, interests, and concerns, and therefore to search for viable means of reconciliation. Belief systems in the cultural environment offer readily available mental frameworks for need satisfaction and therefore represent viable options for reconciliation. Individuals are able to improve their subjective utility if they find a belief system — among those on offer-that satisfies their psychological and other needs, interests, and concerns.

Belief systems may therefore be assessed not only in terms of accuracy, that is, how well they account for known facts, but also desirability, that is, how well they fulfill psychological needs and motives (Bénabou \& Tirole, 2016, p. 142; see also Kunda, 1990). Presumably, the individual's choice of an ideology is shaped not only by how well it serves his or her psychological needs (including needs for accuracy; e.g., see Thompson et al., 1994; Trope, 1979) but also by external factors, such as the costs of information searches and the cultural availability of various ideological alternatives. For the sake of simplicity, we start by describing how 
individuals first evaluate the menu of ideological options based on their needs, and then consider possible trade-offs. That is, we propose that there is something like a two-step ideological choice procedure, which may involve non-conscious as well as conscious processing in either step: (1) First, people evaluate ideological offers based on how well they match their own psychological (and material consumption) needs; (2) Second, people select an ideology on the basis of the ideological reconciliation (the evaluation in the first step) and the generated utility, given various conditions and constraints (such as information costs). Over time, through a process of trial and error — and given a rich enough informational supply in the political environment- the individual is likely to settle upon a belief system that satisfices (or even optimizes, depending upon external constraints) the resolution of his or her needs and demands.

For any individual $j$ there is a set of fairly intangible psychological needs, interests, and concerns, such as those listed in Table 1 . These involve more than desires for physical safety and tangible goods such as food and water. Thus, for the sake of simplicity, we divide $j$ 's system of needs into two distinct sets: (i) a subset of psychological needs, such as needs for order, closure, autonomy, control, self-esteem, self-efficacy, social belongingness, and so on; and (ii) a second subset of needs that is more closely related to material desires for goods and services. We begin by first considering the role of psychological needs before incorporating consumption demands.

\section{Expected Value Arising from the Satisfaction of Psychological Needs}

As noted previously, there is a very large number of psychological needs that have been identified in the psychological literature. We assume that each person (superscript) $j$ has a set of psychological needs, such as need for order, control, self-esteem, etc. Each need component (subscript $i$ ) stands for such a need, while the index number $-1<N_{i}^{j}<1$ describes the desired extent of need satisfaction for component $i$ by individual $j$. For example, if the need $i=$ 
uncertainty avoidance takes the maximum scale value of +1 this indicates that the individual wishes to avoid uncertainty at all cost. If the scale value is -1 , conversely, the individual possesses a maximal desire for uncertainty, so that she would much rather experience novel, unpredictable, and unfamiliar events than predictable, familiar events. A second example is the need $h=$ conformity. An individual may desire a shared sense of reality with like-minded others above all else because they experience disagreement and deviance as extremely painful or threatening. Their need index for conformity would be close to the maximum of +1 . However, if person feels that conformity is boring, unpleasant, or confining and are therefore strongly averse to it, the index would show a negative scale value that approaches -1 . Assuming that the set of psychological needs has $n$ elements, a $n$-dimensional vector describes $j$ 's psychological needs. Mental needs in this model are defined by a $n-$ dimensional vector with $n$ as the need dimension and $i$ the need component.

$$
N^{j}=\left(\begin{array}{c}
N_{1}^{j} \\
\vdots \\
N_{i}^{j} \\
\vdots \\
N_{n}^{j}
\end{array}\right)
$$

Thus, $N^{j}$ describes the complete set of $j^{\prime} s$ psychological needs, and $j$ is motivated, perhaps strongly, to satisfy these needs. If an individual has a $n$-dimensional vector of mental needs, he or she will therefore seek, consciously or non-consciously, to find means of serving all elements of that vector as fully as possible and therefore to search actively for reconciliation.

Consistent with functional approaches to the study of attitudes, beliefs, and opinions (Adorno et al., 1950; Allport, 1954; Eagly \& Chaiken, 1993; Jost, 2006, 2020; Kay \& Eibach, 2013; Kelman, 1961; Lane, 1969; Smith, Bruner, \& White, 1956; Tomkins, 1995), we proceed on the assumption that belief systems and ideologies provide significant opportunities for 
psychological need satisfaction. For instance, certain belief systems may help individuals to address epistemic, existential, and relational needs to manage uncertainty, threat, and social deviance or discord (Jost et al., 2003a, 2009). Adopting a suitable ideology can therefore increase subjective utility for the individual, and the choice of an ideology may be made on the basis of expectations about subjective utility.

Returning to our formal model, the term ideology or belief system refers to a $n-$ dimensional vector $I_{K}$, where " $K$ " is the name of a particular ideology (e.g., liberalism, conservatism, socialism, fascism, anarchy, etc.). For each element $i$ of this vector, $I_{K i}$ provides a specific belief system that has the potential to serve an individual's psychological needs. The index number $-1<I_{K i}<1$ indicates the degree or intensity with which dimension $i$ is expected to be addressed by ideology $K$,

$$
I_{K}=\left(\begin{array}{c}
I_{K 1} \\
\vdots \\
I_{K i} \\
\vdots \\
I_{K n}
\end{array}\right)
$$

For example, if need dimension $i=$ order and ideology $K$ satisfies $i$ to a very high degree by maintaining strict social control and rigorously enforcing disciplined, rule-governed behavior, index $I_{K i}$ takes a value close to the maximum of +1 . That is, if $K$ promises an extremely high degree of social order (as in cases of fascist ideology or highly authoritarian forms of conservatism), it strongly serves the need for $[i=\operatorname{order}]$ [ $\left.I_{K i}=1\right]$. If ideology $K$ refers to anarchy, on the other hand, $I_{K i}$ would take a value close to the minimum of -1 .

In this way, belief systems can be assessed in terms of how well they serve the subjective need vector of individual $j$. For each dimension $i$, the distance between $j$ 's desired level of with respect to need $i$ and the expectation of its satisfaction by ideology $K$ is:

$$
d_{K i}^{j}=\left|I_{K i}-N_{i}^{j}\right|
$$


That is, for each dimension $i$ we can indicate the distance between an ideology and the psychological needs of an individual. Estimating the distance is easy for each individual dimension $i$, but the challenge is in how to determine the distance between an entire belief system $I_{K}$ and the complete set of needs of person $j$. We need to know, in other words, how well a given ideology subjectively addresses the entire constellation of psychological needs, interests, and motives of a given individual.

To tackle this issue, we use a multi-dimensional distance measure. Distance measures have been well known in political choice and voting theory since Anthony Downs' (1957) classic article, "An Economic Theory of Political Action in a Democracy" (e.g., Berry \& Pakes, 2007; Caplin \& Nalebuff, 1991; Davis, Hinich \& Ordebook, 1970; Hinich \& Munger, 1994; Jackson, 2014; Schofield, 2007). However, we depart from these previous models in two ways. First, a distance theory of voting is generally used to understand voting behavior at the aggregate level of analysis. For this purpose, variations of Euclidean distance are simplest and most appropriate and therefore most often applied. We are focused instead on the structure of the individual's choice of ideology — why a given person opts for a particular belief system. Therefore, we adopt a more general modified Minkovski distance measure that, because of its versatility, enables us to interpret various parameters when it comes to determining how close an ideology is to the individual's preferences.

A second difference between our approach and other models of distance-voting is that we focus on belief systems as wholes, whereas other models have typically focused on individual policy positions, as in the case of the median voter theorem (e.g., see Hinich \& Munger, 1994, Chapter 4). According to our model, the subjective appeal of an ideology is determined straightforwardly by the distance between the individual's needs and the placement of an 
ideology on those need dimensions. So, distance in this context directly relates to psychological (and other) needs and the way that an ideology is or is not expected to satisfy these needs. The greater the distance, the worse a given ideology serves the needs of the person.

The distance measure is defined in equation (4), in which $D_{K}^{j}$ represents the distance between the needs of individual $j$ and the expectation that those needs will be resolved by ideology $K$. This measure conveys the distance between the perceived reconciliation provided by $K$ and the ideal state of reconciliation specified by the need vector of individual $j$. In other words, the distance measure describes how well the framework of ideology $K$ serves the needs of individual $j$. At the same time, we depart from the standard Minkovski definition and suggest a modified, more general measure that integrates potential weights $\alpha_{i}^{j}$ for the various need dimensions, on the assumption that individuals vary in how important a given need is to them. Parameter $\rho$ is interpreted in greater detail below.

$$
D_{K}^{j}=\left(\alpha_{1}^{j}\left(d_{K 1}^{j}\right)^{\rho} \ldots+\ldots \alpha_{i}^{j}\left(d_{K i}^{j}\right)^{\rho} \ldots+\ldots \alpha_{n}^{j}\left(d_{K n}^{j}\right)^{\rho}\right)^{\frac{1}{\rho}}
$$

Next, to identify the ideology on offer that best serves the individual's psychological needs we switch from a measure of distance to estimating the degree of match or correspondence (e.g., see Jost et al., 2003a, 2003b). Thus, we indicate the extent to which ideology $K$ serves need dimension $i$ of individual $j$ and matches-or, in Tomkins' (1995) terminology, resonates with $-j$ 's psychological needs. Thus, we define the inverse of the distance to indicate the extent to which $K$ is perceived as satisfying $j^{\prime}$ s needs with respect to dimension $i$ and refer to this measure of "matching" as:

$$
m_{K i}^{j}=\left(d_{K i}^{j}\right)^{-1}
$$


A good match (higher values of $m_{K i}^{j}$ ) indicates that ideology $K$ serves the need dimension $i$ of individual $j$ very well, while a poor match (lower values of $m_{K i}^{j}$ ) indicates that it does not.

According to (5), the inverse of the distance, the matching measure $m_{K i}^{j}(K)$, expresses the extent to which a given ideology is expected to satisfy the individual's needs on a certain level (e.g., the extent to which authoritarian conservatism is expected to satisfy high levels of uncertainty avoidance and conformity). By replacing (4) with (5) the modified Minkovski distance can be rewritten as:

$$
D_{K}^{j}=\left(\alpha_{1}^{j}\left(m_{K 1}^{j}\right)^{-\rho}+\ldots+\alpha_{n}^{j}\left(m_{K n}^{j}\right)^{-\rho}\right)^{\frac{1}{\rho}}
$$

If the inverse of Minkovski distance is regarded as an overall measure of closeness or correspondence between an ideology $K$ and the set of psychological needs of individual $j$, the strength of the correspondence can be indicated by the overall match value $M_{K}^{j}=\left(D_{K}^{j}\right)^{-1}$. Accordingly, we obtain

$$
M_{K}^{j}=\left(\alpha_{1}^{j}\left(m_{K 1}^{j}\right)^{-\rho} \ldots+\ldots \alpha_{i}^{j}\left(m_{K i}^{j}\right)^{-\rho} \ldots+\ldots \alpha_{n}^{j}\left(m_{K n}^{j}\right)^{-\rho}\right)^{-\frac{1}{\rho}}
$$

and refer to $M_{K}^{j}$ as the match-value function that describes how ideology $K$ serves individual $j$ 's vector of needs, and how this match is subjectively valued or appreciated by $j$. Thus, the extent to which a given belief system serves all of the need dimensions affects its evaluation in a very complicated manner. However, it is possible to describe systematically how the match value function transforms the degree of matching for every need dimension $i$ into an overall summary evaluation of an ideology by $j$.

A high match value of $M^{j}=\left(\sum \alpha_{i}^{j}\left(m_{i}^{j}\right)^{-\rho}\right)^{-\frac{1}{\rho}}$ indicates that this ideology serves all need dimensions in a way that is highly valued by the individual. Because the match value 
function meets all of the formal criteria of a constant elasticity of substitution (CES) function, it can be interpreted in a manner that is similar to that of a CES utility function. This makes it easier to describe the characteristics of the evaluation system.

As shown in Figure 1, the first instrument is the locus of constant match values, which we refer to as the indifference curve $\bar{M}^{j}$. An indifference curve shows which combinations of ideological offers obtain the same subjective level of appreciation or evaluation for each need dimension. In Figure 1, curves that are located in the Northeast direction represent ideologies with higher match values (subjective utility). That is, indifference curves that are located there indicate that the individual's psychological needs are better served by those ideological offers. In a multidimensional system such as this one, many components simultaneously determine how a particular combination of matches is evaluated. For illustration purposes, consider a system with only two need dimensions, $i$ and $h$ (uncertainty avoidance and conformity). The match values of $m_{i}$ and $m_{h}$ indicate the degree to which a given ideology serves these two needs, respectively. But how do we determine which ideology serves these needs best?

As indicated by the constant $\bar{M}^{j}$, the same value can be generated by ideologies that serve different combinations of $m_{i}$ and $m_{h}$. In theory at least, the need dimensions should be substitutable for one another, so that an ideology that is perceived as satisfying some need dimensions but not others might be evaluated just as favorably as another ideology that satisfies a different set of need dimensions. It is therefore useful to recognize that individuals may differ in terms of which need dimensions are and are not highly substitutable. We may think of these differences as "biased needs" in a statistical sense (the tendency to give stronger weight to a particular need dimension), without implying anything about ideological accuracy.

The idea, quite simply, is that serving a particular need dimension is of higher importance 
to some individuals than others. For some people, needs to reduce uncertainty and attain a sense of order, structure, and closure may be extremely important, whereas for others needs for freedom, autonomy, and individual uniqueness may predominate (see Jost, 2017). Figure 1a shows how biased needs translate into the system of indifference curves for individual $j$. We focus on the bias for need $i$. A strong need bias for $i$ means that the degree to which need $i$ is served by a particular ideology must be relatively high for that individual, and so the ratio $m_{i}^{j} / m_{h}^{j}$ must also be high. Thus, for any given overall match value $\bar{M}^{j}$ (and the slope of the indifference curve), $j$ desires a relatively high ratio of $m_{i}^{j} / m_{h}^{j}$. This indicates a stronger preference for addressing need $i$ than $h$. Therefore, the system of indifference curves of $j$ reflect a strong preference for serving $i$ (uncertainty avoidance). As shown in Figure 1a, $j$ exhibits a strong bias for need $i$, and so angle $\alpha$ indicates a high need preference for dimension $i$. The system of individual $m$, on the other hand, exhibits a strong bias for need dimension $h$, as angle $\beta$ with $\tan \beta$ indicates a high preference for $h$ (conformity).

By identifying the role of "biased needs" we focus on the individual's tendency to gravitate toward belief systems that are expected to satisfy one or more specific need dimensions. They are therefore likely to find reconciliation with a belief system that addresses needs that are especially pronounced, even if other (less pronounced) needs would be better served by a different belief system. One example is a biased need for safety, which might be induced by exposure to terrorist attacks, pandemic diseases, or economic crises. Individuals who otherwise might have selected an ideology based on other need dimensions (such as integrative complexity, empathy, or autonomy) may come to value safety more highly than other need dimensions because of external threats, and this could lead them to shift their preferences in the direction of an ideology that promises increased safety above all else, such as authoritarian 
conservatism (see Jost et al., 2017).
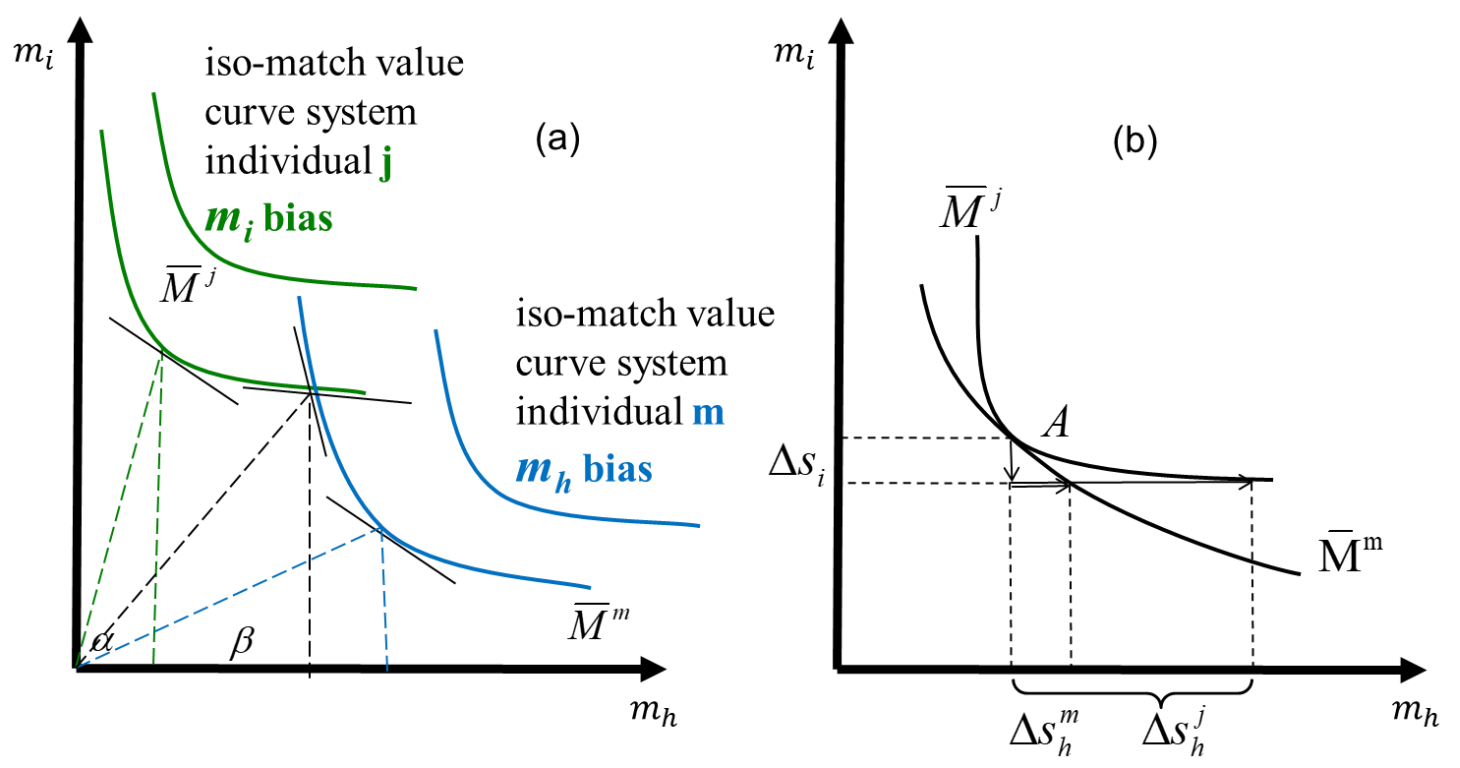

Figure 1: Characteristics of match value functions: Indifference curves

A second property of the indifference curve system illustrates how needs may substitute for or complement one another. Substitutability and complementarity are depicted in Figure $1 \mathrm{~b}$. The two indifference curves represent the shape of a whole system of indifference curves, with one system representing individual $j$ 's preferences and the other the preferences of individual $m$. The shape of $m$ 's indifference curve $\bar{M}^{m}$ implies that this individual would easily substitute need dimension $i$ for need dimension $h$ without negatively impacting the overall match value. Axis $m_{i}$ covers the extent to which need $i$ is served, and axis $m_{h}$ covers the extent to which need $h$ is served. Starting at point $A$ and moving along individual $m$ 's indifference curve $\bar{M}^{m}$ shows that without a loss of the overall match value, individual $m$ may easily forgo some serving of need $i\left(\Delta m_{i}\right)$ if, in return, need $h$ is well-served ( $\Delta m_{h}^{m}$ ). For this individual, any 
anticipated loss of need satisfaction with respect to certainty would be compensated for by an equivalent increase in satisfaction of conformity.

For individual $j$, however, there is a different relationship between the two need dimensions (see Figure 1b). Starting again at point $A$ and moving along $j$ 's indifference curve $\bar{M}^{j}$, we see that the two types of need satisfaction are not completely interchangeable. In particular, a great deal of serving of need $i\left(\Delta m_{i}\right)$ is required to make up for a small loss in the serving of need $h\left(\Delta m_{h}^{j}\right)$. For this individual, even a small decrease in the expected satisfaction of the need for conformity is more consequential than a small decrease in uncertainty reduction. For a different person the opposite may well be true: a small decrease in prospects for uncertainty reduction may be more consequential than an equivalent decrease in satisfaction of the need for conformity. The modified Minkovski distance measure allows us to describe these kinds of asymmetric effects with respect to tradeoffs among different types of need satisfaction.

Thus far, our discussion establishes three things. First, with a formal model, which (to our knowledge) is the first of its kind, it is possible to describe how ideologies that are present in the informational environment can provide viable reconciliation options to address underlying psychological needs. Second, we show that the process of evaluating ideological alternatives and selecting among them can be described using well-known economic and political instruments. Third, when viewed from another perspective, we have the beginnings of a model in which the characteristics of belief systems are understood to reflect key aspects of human psychology.

\section{Expected Value Arising from the Satisfaction of Consumption Needs}

The previous section focused on the role of psychological needs, but we know that there is a second class of needs, namely material or consumption preferences, that play a decisive role in ideological preferences. Many social historians, for instance, attribute the failure of 
Communist ideology to maintain legitimacy in Eastern Europe in the late 1980s to the fact that citizens lost faith in the regime's ability to provide essential goods and services (White, 1986). In this section, we expand our model of ideological choice to incorporate a set of material needs or consumption desires. Individual $j$ 's preferences are now characterized by two sets of needs: (a) relatively intangible, psychological needs, such as those discussed previously, and (ii) needs and desires for material consumption, which we refer to as tangible preferences.

To incorporate these two types of needs in our model, it is necessary to specify how they relate to one another. We may start by assuming that it is possible to distinguish psychological factors from the more tangible world of goods and services. We recognize that this is a simplifying assumption, because it is easy to generate examples in which consumer purchases might address psychological concerns. For instance, buying firearms could address psychological needs for control and safety (Pierre, 2019; Shepherd \& Kay, 2017). More complicated models could address the interplay of psychological and consumption needs in accounting for ideological preferences, but for the time being we proceed as if the two types of needs are separable.

Therefore, we proceed with the development of a utility function that describes the individual's ideological preferences in a broad utilitarian manner. The two relevant dimensions are the match value of an ideology $M^{j}$ (the extent to which an ideology serves the psychological needs of individual $j$ ) and the level of consumption of material goods $C^{j}$. Thus, we can represent the utility function as

$$
U^{j}=U^{j}\left(M^{j}, C^{j}\right)
$$

This utility function looks similar to pure economic preference systems and instruments used in microeconomics to describe the individual's decision-making. The match value of psychological 
need satisfaction is nested in a simple specification of a utility function. We discuss the preference structure of an individual and characterize these preferences for reconciliation options that serve his or her intangible (psychological) and tangible (material) needs. In this utility function, $\beta_{M}^{j}$ and $\beta_{C}^{j}$ describe the weight assigned to the two dimensions, whereas $\gamma$ is a parameter that determines the substitutability of the two dimensions:

$$
U^{j}=\left[\beta_{M}\left(M^{j}\right)^{-\gamma}+\beta_{C}\left(C^{j}\right)^{-\gamma}\right]^{-\frac{1}{\gamma}} .
$$

A discussion of the characteristics of this two-dimensional CES utility function may be slightly tedious, because it formally parallels the earlier discussion, but it yields some new and interesting implications. In Figure 2a we illustrate indifference curves for the utility function (7). In this context, an indifference curve reveals combinations of match values for psychological and consumption needs that generate the same utility. Indifference curves located in the northeastern direction imply higher subjective utilities overall.

An individual $j$ may be said to possess a consumption bias if his or her indifference curve system is located closer to the $\mathrm{C}$-axis, resulting in a relatively high ratio of $C^{j} / M^{j}$ (see Figure 2a). This means that high expectations of material consumption are more important for this person when it comes to ideological preferences than a strong match in terms of psychological needs. His or her interests are relatively materialistic, so the ideology chosen is likely to be focused on enhanced consumption possibilities. A different individual $i$ may be said to possess a psychological need bias if his or her indifference curve system is located closer to the M-axis, indicating that the resolution of psychological needs is more important than high expectations of material consumption when it comes to determining ideological preferences. For this person, it is more important to select an ideology that addresses his or her psychological 
needs, interests, and concerns rather than consumption possibilities.
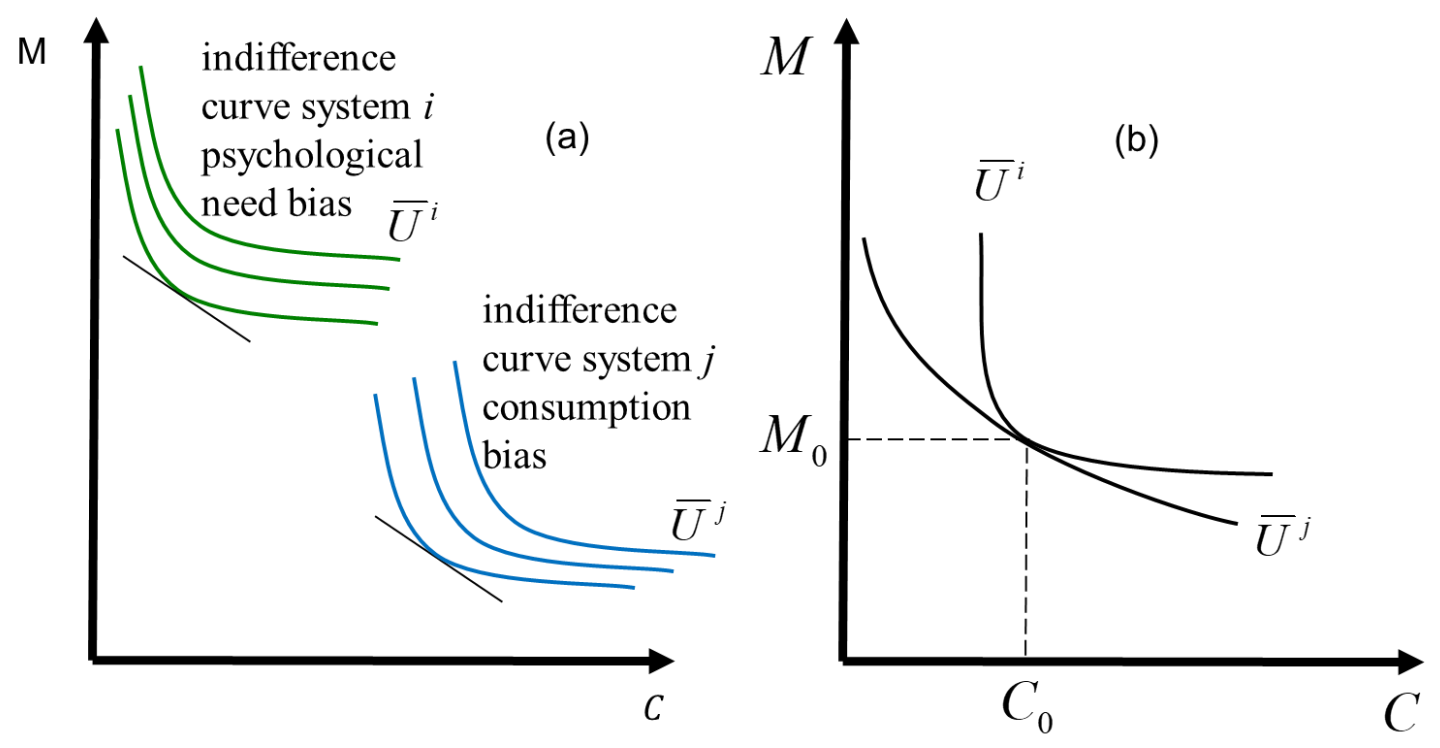

Figure 2: Characteristics of a preference system: (a) biased preferences, psychological vs. consumption needs, and (b) substitutability of psychological and consumer preferences

Next we consider the issue of substitutability between the two dimensions. Figure $2 b$ illustrates this concept. How likely is it that a given individual would forego psychological need satisfaction in order to obtain more consumption possibilities (and vice versa)? While $j$ would easily exchange one dimension for the other, for $i$ the two dimensions are complementary. This characteristic of the preference system is revealing, because it tells us something about the utility of reconciliation options that do not necessarily satisfy specific psychological needs. If a government provides opportunities for consumption and economic growth while exercising repressive policies, a majority of citizens may not feel worse off, if they (like individual $j$ ) regard the increase in consumption as compensation for the fact their psychological needs, such as needs for autonomy and freedom, are less well-served.

For strongly complementary (non-substitutable) preferences, as shown by the indifference curve of individual $i$ in Figure $2 \mathrm{~b}$, we observe an L-shaped function. In this case, an 
increase in consumption opportunities would not improve the overall level of utility if an individual's psychological needs, such as needs for autonomy and freedom, are poorly served. For this individual, increased consumption possibilities cannot compensate for repression and/or a lesser degree of satisfaction of his or her psychological needs.

Thus far, we have described the individual's system of ideological evaluation (the demand side) as a utility function without considering the role of external constraints and opportunities (the supply side). One dimension of the utility function is the match value $M$, which refers to the extent to which the individual expects that his or her psychological needs will be served, and a second dimension refers to expectations about material consumption $C$. In the next section we propose that ideologies represent viable reconciliation options that relate to both psychological and consumption needs.

\section{Ideological Options for Need Reconciliation}

From the perspective of the individual, an ideology $K$ is characterized by the extent to which it serves intangible (psychological) and tangible (consumption) needs $\left[M_{K}, C_{K}\right]$ and is therefore an opportunity for need reconciliation. Two questions arise. First, how does a person pick out the subset of consistent choice options from the set of all belief systems? Second, how does he or she identify the belief system that provides the best option for need reconciliation?

To identify consistent choices, we assume that on some level individuals understand that their long-term consumption possibilities are not independent of the belief systems they adopt. For example, if someone chooses an egalitarian ideology, such as socialism, he knows - if he is relatively wealthy - that he will be taxed according to the ideological rule, which will reduce his consumption options. If he is instead relatively poor, he will gain consumption opportunities from choosing the egalitarian ideology. This implies that an individual's personal situation and 
life circumstances matter when it comes to choosing a particular belief system. In other words, the set of choices itself is not independent of one's personal income and social class position.

For the sake of simplicity, we assume that the individual knows his or her social and economic position and estimates to the extent to which an ideology $K$ serves psychological needs (match value $M_{K}$ ) and the effects of this ideology on income and consumption possibilities $\left(C_{K}\right)$, including taxes or subsidies implied by $K$. To return to the example above, let us assume that individual $j$ has a given gross income $\bar{Y}$ and is rich. He is aware that an egalitarian ideology would tax a rich person like him at level $\tau_{K}$. Thus, $K$ implies a strong reduction in disposable income $Y$ to the level

$$
Y_{K}=\bar{Y}-\tau_{K}
$$

For every ideology under consideration, implications for disposable income are relevant, in addition to expectations about psychological need satisfaction $\left(M_{K}\right)$.

To make a choice about ideologies the individual must collect at least some information about the implications of various ideologies for the potential satisfaction of psychological and consumption needs. We have already suggested that an individual $j$ has various psychological needs on dimensions ranging from $i$ to $n$, and that an ideology $K$ is expected to serve each need dimension to some degree $\left(\widetilde{m}_{K i}^{j}\right)$. So $\widetilde{m}_{K i}^{j}$ represents the potential extent to which ideology $K$ serves $j$ 's needs on dimension $i$.

At the same time, it is necessary to account for the fact that only information exposure can reveal this potential degree of match. Therefore, we introduce a revelation factor $\left(R_{K i}^{j}\right)$, which represents the extent to which $\widetilde{m}_{K i}^{j}$ is subjectively revealed by information to which the individual has been exposed. Therefore, the currently perceived match value $m_{K i}^{j}$ is the potential for need satisfaction $\widetilde{m}_{K i}^{j}$ times the revelation factor $R_{K i}^{j}$ : 


$$
m_{K i}^{j}=\tilde{m}_{K i}^{j} R_{K i}^{j}
$$

The revelation factor $R_{K i}^{j}$ is determined by information $I_{K i}^{j}$ about the extent to which ideology $K$ addresses individual $j$ 's need on dimension $i$. Thus, we define $R_{K i}^{j}$ as a function of relevant information about ideology $K$ collected by individual $j, R_{K i}^{j}=R_{K i}^{j}\left(I_{K i}^{j}\right)$. To standardize the revelation factor to range from $0 \%$ and $100 \%$ we add the following specification:

$$
R_{K i}^{j}=\left(1-e^{-I_{K i}^{j}}\right)^{\varepsilon_{K}}
$$

where $0<\varepsilon_{K}<1$ is a parameter that describes the revelation effect from information that the individual has gathered. We can now proceed to discuss the effect of information collection on the perceived aggregate match value of an ideology.

In particular, we focus on the subjective perception of how well an ideology matches one's needs ( $m_{K i}=\widetilde{m}_{K i}^{j} R_{K i}$ ), and this is what determines the aggregate match value of the ideology under evaluation:

$$
M_{K}^{j}=\left(\sum \alpha_{K i}^{j}\left(\tilde{m}_{K i}^{j} R_{K i}\right)^{-\rho}\right)^{-\frac{1}{\rho}}
$$

If we assume for each individual that the revelation effect of information $R_{K i}$ is specific for each ideology $K$, and if we suppose (again for the sake of simplicity) that $R_{K i}$ is identical for each dimension within an ideology $\left(R_{K i}=R_{K j}=R_{K}\right)$ we can describe the perceived match value for an ideology as being dependent on information exposure:

$$
M_{K}^{j}=\left(\sum \alpha_{K i}^{j}\left(\widetilde{m}_{K i}^{j}\right)^{-\rho}\right)^{-\frac{1}{\rho}}\left(1-e^{-I_{K}^{j}}\right)^{\varepsilon_{K}}=\widetilde{M}_{K}^{j}\left(1-e^{-I_{K}^{j}}\right)^{\varepsilon_{K}}
$$

Because only information searches can reveal the match value of an ideology, it is useful to account for the cost of conducting such searches. As noted above, the household's disposable income adjusted for the tax implications of ideology $K$ is $Y_{K}(8)$. This income can be used either 
to consume $C$ or to collect new information at price $p_{K}^{j}$. With the subscript $K$ we indicate that the costs of collecting information may be different for different ideologies $K$. That is, it might be more costly or difficult to obtain information about Communism in the U.S. than in China and more costly or difficult to obtain information about capitalism in Cuba than in the United Kingdom. Furthermore, to understand the implications of a more complex ideology there will be higher costs associated with obtaining information than for simpler ideological narratives. The costs might differ among individuals as a function of educational background and informational environment. On the basis of budget constraints $\left[Y_{K}=\bar{Y}^{j}-\tau_{K}=C_{K}^{j}+p_{K}^{j} I_{K}^{j}\right]$ we see that for a given income, collecting information reduces consumption possibilities:

$$
I_{K}^{j}=\frac{\bar{Y}^{j}-\tau_{K}^{j}}{p_{K}^{j}}-\frac{1}{p_{K}^{j}} C_{K}^{j}
$$

We can now rewrite (11) and observe that for a given income the perceived match value of an ideology $M_{K}^{j}$ is directly determined by the consumption $C_{K}^{j}$ sacrificed by the individual to collect the relevant information:

$$
\begin{aligned}
& M_{K}^{j}=\widetilde{M}_{K}\left(\left(1-e^{-\frac{1}{p_{K}}\left(Y_{K}-C_{K}\right)}\right)\right)^{\varepsilon_{K}}, \\
& \lim _{C_{K} \rightarrow \bar{Y}} M_{K}^{j}=0, \lim _{C_{K} \rightarrow 0} M_{K}^{j}=\widetilde{M}_{K}
\end{aligned}
$$

Thus, individuals must give up some degree of consumption to obtain more information about an ideology that may serve their psychological needs. As shown in Figure $3 \mathrm{a}$, the curve $M_{K}^{j}\left(C_{K}^{j}\right)$ illustrates the trade-off between material consumption and the reconciliation of psychological and consumption needs provided by ideologies. 

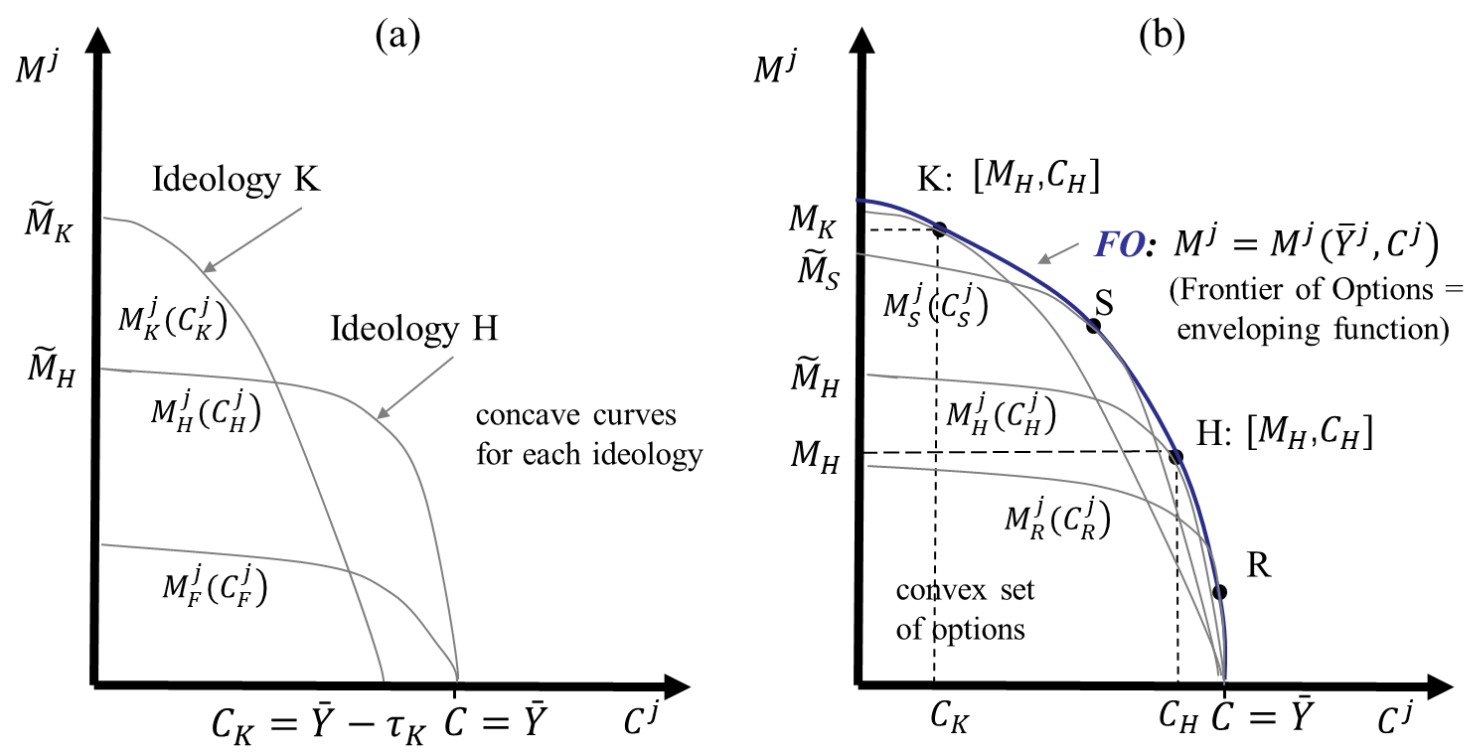

Figure 3: Set of consistent options

This curve is concave in the M-C diagram, insofar as the derivative is $\frac{d M_{K}^{j}}{d \mathrm{C}_{K}}<0$, and

$\frac{d^{2} M_{K}^{j}}{d\left(C_{K}^{j}\right)^{2}}<0$ (see Appendix). If we draw one curve for each ideology $K$ we see that the potential match value of an ideology $\left(\widetilde{M}_{K}\right)$ depends on a number of parameters, including specific information costs $\left(p_{K}\right)$ and effectiveness of information on revelation $\left(\varepsilon_{K}\right)$. As shown in Figure 3a, there is considerable variability in the shapes of curves for ideologies $F, H$, and $K$. One thing that becomes apparent is that curve $M_{F}^{j}\left(C_{F}^{j}\right)$ is subsumed by curve $M_{H}^{j}\left(C_{H}^{j}\right)$. Thus, $F$ with curve $M_{F}^{j}\left(C_{F}^{j}\right)$ is inside $H$ with $M_{H}^{j}\left(C_{H}^{j}\right)$, which means that the match value of $H$ is larger than that of $F$ at every level of consumption. A rationally consistent actor would therefore drop $F$ from the list of viable ideological candidates. The other two curves (for $H$ and $K$ ) intersect, so from a subjective perspective neither is clearly better than the other.

Now we assume that there is a large number of ideologies that differ in terms of information costs and potential match values. As illustrated in Figures 3a and 3b each ideology is 
described by a concave function. For each of these concave functions, such as $M_{K}^{j}=$ $M_{K}^{j}\left(\bar{Y}^{j}, \tau_{K}^{j}, C_{K}^{j}\right)$, the hypograph ${ }^{2}$ is a convex set. We can form the convex set union of these hypographs and with a large number of such hypographs we can assume that the boundary of this set union is a differentiable concave function. In other words, the enveloping curve of all $M_{K}^{j}$ curves describes all possible consistent options that are available. It represents the frontier of options $(F O)$.

$$
M^{j}=M^{j}\left(\left(\bar{Y}^{j}, \tau_{K}^{j}, C^{j}\right) \text {, with } \frac{d M_{K}^{j}}{d C_{K}^{j}}<0 \text {, and } \frac{d^{2} M_{K}^{j}}{d\left(C_{K}^{j}\right)^{2}}<0\right.
$$

Why do we construct this envelope curve and what does it tell us? In this case the envelope curve identifies the efficient/consistent choice options of all ideological offers as well as trade-offs between high match values that serve psychological needs and consumption preferences. So, the enveloping curve is a kind of menu of the individual's viable ideological options. In the next step the individual can choose one point on the curve that he or she likes best, such as $\left(M_{H}, C_{H}\right)$. It is then possible to trace this choice back to a specific ideology (in this case $H$ ), because the point is defined by the tangent of the envelope curve and the ideology curve $H$. Each point on the frontier of options (envelope) therefore stands for a viable ideological option (as one element in the set of all efficient and consistent options) that an individual can choose based on his or her particular combination of tangible and intangible needs.

In the most typical and straightforward cases, we see that there is a trade-off between the two dimensions of psychological need satisfaction and utility from consumption opportunities. That is, the individual can only increase psychological need satisfaction by sacrificing consumption and vice versa. This is again shown in the frontier of options $(F O)$ curve in Figure

\footnotetext{
${ }^{2}$ A hypograph of a function $f: R^{n} \rightarrow R$ is the set of points that are lying below the graph, meaning $\operatorname{hypo}(f)=\{(x, \mu): \quad \mu \leq f(x)\} \in R^{n+1}$
} 
4a. So, which belief system would individual $\boldsymbol{j}$ adopt?

To answer this question we must combine the two instruments, the utility system that describes matching values for psychological and consumption needs and the viable choice options offered by various ideologies comprising the frontier of options. The frontier of options, again, is the envelope curve that describes the set of consistent options based on the individual's combination of tangible and intangible needs. Figure 4a displays the set of consistent options and indifference curves for two individuals, $j$ and $m$. To the extent that they are behaving in a rationally consistent manner, they will choose ideologies based on their expectations of need fulfilment and consumption preferences.

If $j$ has a strong psychological need bias (as described earlier), she is likely to choose something like ideology $K$. This is because $K$ is highest in terms of subjective utility (the point where the indifference curve is tangent to the envelope curve), given $j$ 's particular combination of tangible and intangible needs. The implication is that for someone with a strong psychological need bias, the disutility of paying taxes, investing in information searches, and having fewer consumption opportunities is more than compensated for by a gain in utility from subscribing to an ideology that addresses psychological needs, such as empathy, openness, and tolerance of ambiguity.

The result reverses if the individual has a strong consumption bias. Even if individual $\boldsymbol{m}$ generally likes egalitarian ideologies because they serve his psychological needs, he is likely to choose something like $\boldsymbol{H}$ to address his consumption preferences, because $\boldsymbol{H}$ represents the highest indifference curve individual $\boldsymbol{m}$ can reach given his frontier of options. For instance, he may gravitate toward a free market ideology that promises low taxes and more opportunities for consumption, despite having a psychological affinity for egalitarian ideas. If an individual has 
symmetrical preferences, he or she will likely choose an intermediate ideology such as $\boldsymbol{S}$, which combines moderate redistributive taxation policies and some support for social welfare (i.e., liberalism rather than socialism). As shown in Figure 4a, higher indifference curves are possible in principle for both individuals. However, they cannot be chosen because they lie beyond the frontier of options, which means that they are not culturally available.
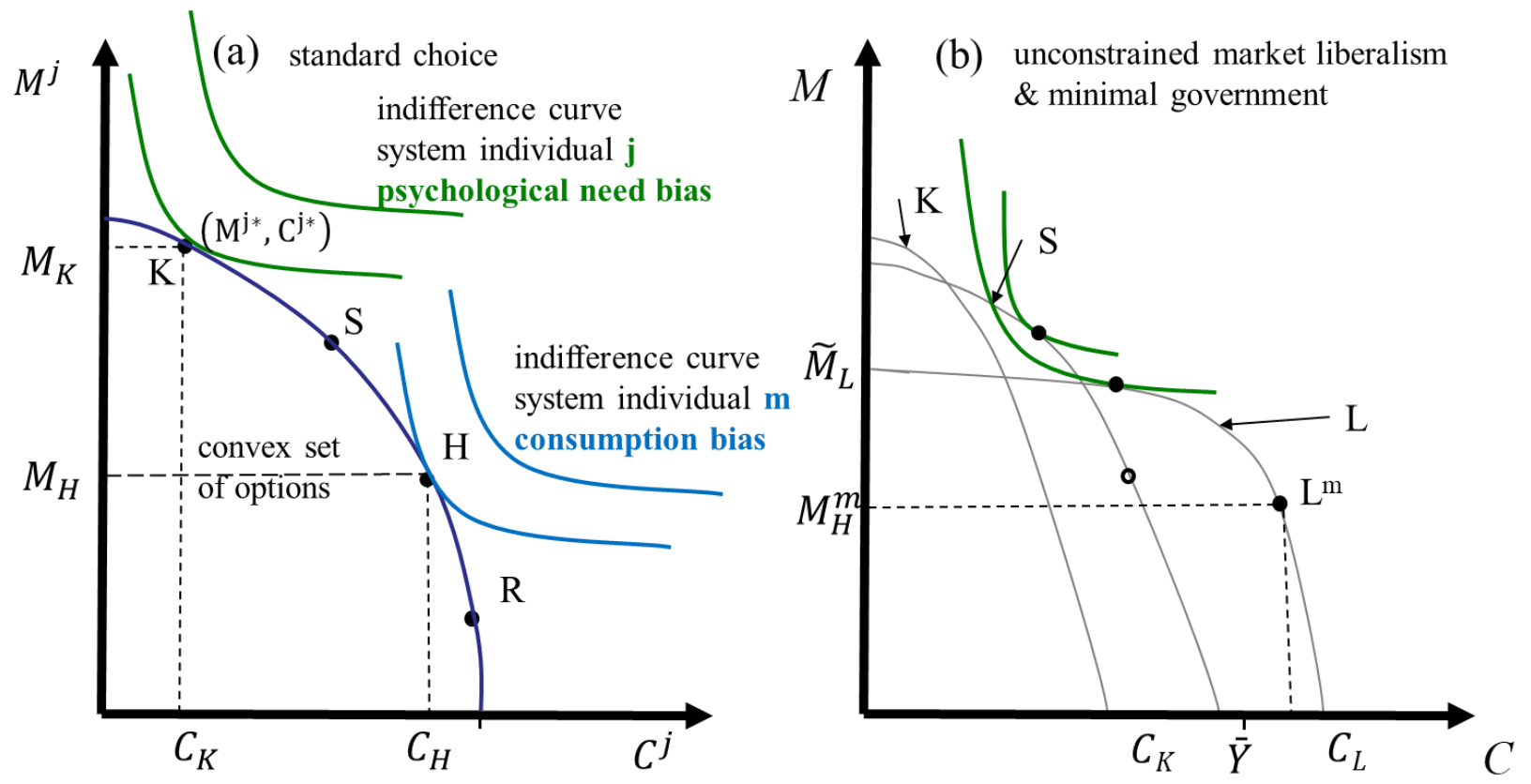

Figure 4: The choice of an ideology (a) given the individual's psychological needs, consumption preferences, and the feasible set of options; (b) choice variations

The situation illustrated in Figure $4 \mathrm{a}$ can also be represented as a formal choice problem. In this case the individual $j$ maximizes utility (7) subject to his or her frontier of options (14):

$$
\begin{aligned}
& \max _{C^{j}} U^{j}=\left[\beta_{M}\left(M^{j}\right)^{-\gamma}+\beta_{C}\left(C^{j}\right)^{-\gamma}\right]^{-\frac{1}{\gamma}} \\
& \text { s.t. } M^{j}=M^{j}\left(\bar{Y}^{j}, \tau_{K^{j}}^{j} C^{j}\right)^{-},
\end{aligned}
$$


The solution to this standard choice problem is that the individual consults his or her menu of choices, which is captured graphically by the frontier of options, the $F O$-curve in Figure $4 \mathrm{a}$. The person then selects a point at which his or her psychological and consumption needs are subjectively satisfied; in this way the highest utility is generated, given other constraints and opportunities. For instance, to the extent that individual $j$ in Figure $4 \mathrm{a}$ is behaving in a rationally consistent manner, he or she is likely to choose the combination of $M^{j *}$ and consumption level $C^{j *}$. This pair $\left(M^{j *}, C^{j *}\right)$ on the $F O$-curve stands for a particular ideology, which is $K$ in this example $\left(M^{j *}=M_{K}, C^{j *}=C_{K}\right)$.

$$
\left.\begin{array}{rl}
M^{j *} & =M_{K} \\
C^{j *} & =C_{K}
\end{array}\right\} \rightarrow \text { ideology } K .
$$

(For a formal proposition and a proof see the appendix).

\section{General Discussion}

Ideologies, whether political, religious, spiritual, or scientific, provide a network of attitudes and beliefs that "serves as a guide and compass through the thicket" of social and political life (Ball \& Dagger, 1991, pp. 1-2). A scholarly focus on the social, cognitive, and motivational underpinnings of belief systems suggests that they reflect, among other things, the attempts of individuals and groups to satisfy various psychological needs (Jost et al., 2003a, 2009; Jost, 2006, 2020). This is sometimes referred to as a "functional approach" to the study of beliefs, opinions, and values (Adorno et al., 1950; Eagly \& Chaiken, 1993; Kay \& Eibach, 2013; Kelman, 1961; Lane, 1969; Smith et al., 1956). At the same time, the choice of a specific ideology also depends on the availability of options in one's cultural environment. Ultimately, it is impossible to explain ideological outcomes without taking into account both supply and demand characteristics. 
In an open, democratic, and pluralistic society, ideological alternatives co-exist more or less peacefully. At the same time, they are always competitors, for ideologies are "general ways of going about things, suggesting approaches, facilitating interpretation and communication, whilst blocking alternative approaches or interpretations" (Gellner, 1959, p. 232, emphasis added). In extreme cases, ideological conflict may even provoke violence, war, genocide, terrorism and other atrocities (Dember, 1991). In totalitarian contexts, the state holds a monopoly not only on markets for goods and services but also the market for ideology. In liberal democracies, the ideal is that citizens are free to select their own ideological preferences, much as diners are free to select their own meals from a menu of options. In this article, we have developed a formal model to describe and illustrate precisely this type of ideological choice.

In particular, we have sought to address two major questions. First, why do individuals adopt the specific belief systems they do? Second, how can we use the techniques of standard rational choice modeling to illuminate this process? To address these questions, we adopt methodological tools taken from "characteristics demand theory" (Berry \& Pakes, 2007), the distance theory of voting (Hinich \& Munger, 1994), and standard choice models in economics, and combine them with theory and research in psychology. With these tools, it is possible to provide a formal analysis of the ways in which individuals make ideological choices (given resource constraints and aspects of their informational environments) and explain, from a psychological perspective, individual-level variation in the decision-making process.

For the most part, we have focused on demand-side processes in this article. By taking into account the psychological and material consumption preferences of individuals we are in a better position to understand the process of ideological choice, including the resolution of tradeoffs between the costs of information acquisition and expected gains in terms of the subjective 
utility of finding a good ideological match. The more information that is processed pertaining to a given ideology, even if the information is presented in a limited or somewhat biased manner, the more an individual is able to detect a perceived match between his or her needs and the ideological "offer." However, information searches are costly, and these costs are not evenly distributed across all ideologies. For instance, it is much more costly to learn about an ideology that is culturally unfamiliar, such as feminist ideology in highly traditional and religious societies, as opposed to familiar, as in the case of a "dominant ideology" (Kluegel \& Smith, 1986). Furthermore, some belief systems are simpler and easier to understand than others, which might require some knowledge of history or philosophy or some degree of technical or scientific expertise. Putting all of this together, the choice of an ideology depends not only on its psychological need-serving tendencies (the match value) and the individual's resource constraints (e.g., time, income, education, knowledge, etc.), but also on environmental conditions (the ideological market) and informational costs of learning about specific ideologies. The net result of this decision-making process (under circumstances of uncertainty and other constraints) is, in principle, an ideological outcome that address the totality of the individual's needs, interests, and concerns.

One non-obvious implication of our analysis is that people can be "wrong" about which ideology they ought to choose on the basis of their own needs, interests, and concerns. That is, people may not necessarily behave in a rationally consistent manner. In this respect, our decision-making model of political ideology differs from many others in that it is not relativistic, in the sense of assuming that there is no truth of the matter when it comes to ideological preferences. Much as political scientists have devised tools to help citizens "vote correctly" by improving their ability to match their own issue preferences with specific political candidates 
(Lau, Andersen, \& Redlawsk, 2008), our model holds out the hope that people can come to make ideological choices more rationally and, in so doing, to attenuate if not overcome the problem of false consciousness (Jost, 1995, 2020).

\section{Concluding Remarks}

Robert Zajonc (1999) argued that psychology as a science has long been hampered by an inability to account for both rational and irrational forms of behavior using the same unified theoretical (or meta-theoretical) framework. That is, psychological scientists have tended to focus on either rational or irrational forces in human behavior. The model we have introduced here offers the prospect of explaining ideological choices in terms of a wide variety of considerations that individuals may weigh either appropriately or inappropriately. It may therefore help to explain not only why people adopt the specific belief systems they do, but also which belief systems they should adopt, from the perspective of rational choice theory. 


\section{References}

Adorno, T.W., Frenkel-Brunswick, E., Levinson, D.J., \& Sanford, R.N. (1950). The authoritarian personality. New York: Harper and Row.

Allport, G. W. (1954). The nature of prejudice. Reading, MA: Addison-Wesley.

Altemeyer, B. (1998). The other "authoritarian personality." Advances in Experimental Social Psychology, 30, pp. 47-92.

Ariely, D., Loewenstein, G., \& Prelec, D. (2006). Tom Sawyer and the construction of value. Journal of Economic Behavior \& Organization, 60(1), 1-10.

Ball, T., \& Dagger, R. (Eds.) (1991). Ideals and ideology. A reader. New York: Harpers Collins.

Bénabou, R., \& Tirole, J. (2016). Mindful economics. The production, consumption, and value of beliefs. Journal of Economic Perspectives, 30(3), 141-164.

Bettelheim, B., \& Janowitz, M. (1964). Social change and prejudice. Glencoe, IL: Free Press.

Berry, S., \& Pakes, A. (2007). The pure characteristics demand model. International Economic Review, 48(4), 1193-1225.

Bobo, L., \& Hutchings, V. L. (1996). Perceptions of racial group competition: Extending Blumer's theory of group position to a multiracial social context. American Sociological Review, 61(6), 951-972.

Brock, D., \& Rabin-Havt, A. (2012). The Fox effect: How Roger Ailes turned a network into a propaganda machine. New York, NY: Random House.

Caplin, A., \& Nalebuff, B. (1991). Aggregation and social choice: A mean voter theorem. Econometrica: Journal of the Econometric Society, 1-23.

Davis, O. A., Hinich, M. J., \& Ordeshook, P. C. (1970). An expository development of a mathematical model of the electoral process. American Political Science Review, 64(2), 426- 
448.

Deci, E. L., \& Ryan, R. M. (2000). The "what" and "why" of goal pursuits: Human needs and the self-determination of behavior. Psychological Inquiry, 11(4), 227-268.

Denzau, A. T., \& North, D. C. (2000). Shared mental models: Ideologies and institutions. In Lupia, A., Mccubins M.D., \& Popkin S.L. (Eds.), Elements of reason: Cognition, choice, and the bounds of rationality (pp.23-46), Cambridge University Press.

Downs, A. (1957). An economic theory of political action in a democracy. Journal of Political Economy, 65(2), 135-150.

Duckitt, J. (2001). A dual-process cognitive-motivational theory of ideology and prejudice. Advances in Experimental Social Psychology, 33, 41-113.

Eagly, A. H., \& Chaiken, S. (1993). The psychology of attitudes. Orlando, FL: Harcourt Brace Jovanovich College Publishers.

Federico, C. M., \& Malka, A. (2018). The contingent, contextual nature of the relationship between needs for security and certainty and political preferences: Evidence and implications. Advances in Political Psychology, Vol. 39, Suppl. 1, 3-48.

Fehr, E., \& Schmidt, K. M. (1999). A theory of fairness, competition, and cooperation. The Quarterly Journal of Economics, 114(3), 817-868.

Gellner, E. (1959). Words and things: A critical account of linguistic philosophy and a study in ideology. Boston, MA: Beacon.

Gries. T., \& Muller, V. (2020). Conflict economics and human needs. Center for International Economics Working Papers CIE, 135

Hamill, R., Lodge, M., \& Blake, F. (1985). The breadth, depth, and utility of class, partisan, and ideological schemata. American Journal of Political Science, 29(4), 850-870. 
Hardin, G. (1968). The tragedy of the commons. Science, 162(3859), 1243-1248.

Higgins, E. T. (2000). Making a good decision: Value from fit. American Psychologist, 55(11), 1217-1230.

Hinich, M. J., \& Munger, M. C. (1994). Ideology and the theory of public choice. Ann Arbor, MI: University of Michigan Press.

Jackson, J.E. (2014). Location, location, location: The Davis-Hinich model of electoral competition. Public Choice, 159, 197-218.

Jardina, A. (2019). White identity politics. Cambridge University Press.

Jost, J.T. (1995). Negative illusions: Conceptual clarification and psychological evidence concerning false consciousness. Political Psychology, 16, 397-424.

Jost, J. T. (2006). The end of the end of ideology. American Psychologist, 61, 651-670.

Jost, J.T. (2017). Ideological asymmetries and the essence of political psychology. Political Psychology, 38(2), 167-208.

Jost, J.T. (2019). Anger and authoritarianism mediate the effects of fear on support for the far right—What Vasilopoulos et al. (2018) really found. Political Psychology, 40, 705-711.

Jost, J.T. (2020). A theory of system justification. Cambridge, MA: Harvard University Press.

Jost, J.T. (in press). Left \& right: The psychological significance of a political distinction. New York: Oxford University Press.

Jost, J. T., \& Amodio, D. M. (2012). Political ideology as motivated social cognition: Behavioral and neuroscientific evidence. Motivation and Emotion, 36(1), 55-64.

Jost, J.T., Basevich, E., Dickson, E.S., \& Noorbaloochi, S. (2016). The place of values in a world of politics: Personality, motivation, and ideology. T. Brosch \& D. Sander (Eds.), Handbook of value: Perspectives from economics, neuroscience, philosophy, psychology, and sociology 
(pp. 351-374). New York: Oxford University Press.

Jost, J. T., Federico, C. M., \& Napier, J. L. (2009). Political ideology: Its structure, functions, and elective affinities. Annual Review of Psychology, 60, 307-337.

Jost, J. T., Federico C. M., \& Napier J. L. (2013). Political ideologies and their social psychological functions, in: Freeden, M., Sargent, L. T. \& Stears, M. (Eds.), The Oxford Handbook of Political Ideologies (pp. 281-301). Oxford, UK: Oxford University Press.

Jost, J. T., Glaser, J., Kruglanski, A. W., \& Sulloway, F. J. (2003a). Political conservatism as motivated social cognition. Psychological Bulletin, 129(3), 339.

Jost, J.T., Glaser, J., Kruglanski, A.W., \& Sulloway, F. (2003b). Exceptions that prove the ruleUsing a theory of motivated social cognition to account for ideological incongruities and political anomalies: Reply to Greenberg \& Jonas (2003). Psychological Bulletin, 129, 383393.

Jost, J., \& Hunyady, O. (2003). The psychology of system justification and the palliative function of ideology. European Review of Social Psychology, 13(1), 111-153.

Jost, J.T., Sterling, J., \& Stern, C. (2018a). Getting closure on conservatism, or the politics of epistemic and existential motivation. In C.E. Kopetz \& A. Fishbach (Eds.), The motivationcognition interface; From the lab to the real world: A Festschrift in honor of Arie W. Kruglanski (pp. 56-87). New York: Routledge/Taylor \& Francis.

Jost, J.T., Stern, C., Rule, N.O., \& Sterling, J. (2017). The politics of fear: Is there an ideological asymmetry in existential motivation? Social Cognition, 35(4), 324-353.

Jost, J.T., van der Linden, S., Panagopoulos, C. \& Hardin, C.D. (2018b). Ideological asymmetries in conformity, desire for shared reality, and the spread of misinformation. Current Opinion in Psychology, 23, 77-83. 
Kahneman, D. (2011). Thinking, fast and slow. New York: Macmillan.

Kay, A. C., \& Eibach, R. P. (2013). Compensatory control and its implications for ideological extremism. Journal of Social Issues, 69(3), 564-585.

Kelman, H. C. (1961). Processes of opinion change. Public Opinion Quarterly, 25(1), 57-78.

Khalil, E. L. (2011). Rational, normative, and procedural theories of beliefs: can they explain internal motivations? Journal of Economic Issues, 45(3), 641-664.

Kluegel, J. R., \& Smith, P. M. (1986). Beliefs about inequality: Americans' views of what is and what ought to be. Hawthorne, NY: Aldine de Gruyter.

Kunda, Z. (1990). The case for motivated reasoning. Psychological Bulletin, 108(3), 480-498.

Lane, R. (1969). Political thinking and political consciousness. New York: Free Press.

Lasswell, H. D. (1930). Psychopathology and politics. Chicago, IL: University of Chicago Press.

Lau, R. R., Andersen, D. J., \& Redlawsk, D. P. (2008). An exploration of correct voting in recent U.S. presidential elections. American Journal of Political Science, 52(2), 395-411.

Malka, A., \& Soto, C. J. (2015). Rigidity of the economic right? Menu-independent and menudependent influences of psychological dispositions on political attitudes. Current Directions in Psychological Science, 24(2), 137-142.

Maslow, A. H. (1943). A theory of human motivation. Psychological Review, 50, 370-96.

Mason, L. (2018). Uncivil agreement: How politics became our identity. Chicago, IL: University of Chicago Press.

McClelland, D. C. (1961). Achieving society. Simon and Schuster.

McGuire, W.J. (1999). Constructing social psychology: Creative and critical processes. New York: Cambridge University Press.

Milburn, M. A., \& Conrad, S. D. (1996). The politics of denial. Cambridge, MA: The MIT Press 
Murray, H. A. (1938). Explorations in personality: A clinical and experimental study of fifty men of college age. New York: Oxford University Press.

Pew Research Center (2016). Religion in Everyday Life. Religion and Public Life, April 12, 2016. Retrieved from: https://www.pewforum.org/2016/04/12/religion-in-everyday-life/

Pew Research Center (2018). "New Age” beliefs common among both religious and nonreligious Americans. Factank, October 1, 2018. Retrieved from: https://www.pewresearch.org/fact-tank/2018/10/01/new-age-beliefs-common-among-bothreligious-and-nonreligious-americans/

Pew Research Center (2020a). White Evangelicals see Trump as fighting for their beliefs, though many have mixed feelings about his personal conduct. March 12, 2020. Retrieved from: https://www.pewforum.org/2020/03/12/white-evangelicals-see-trump-as-fighting-for-theirbeliefs-though-many-have-mixed-feelings-about-his-personal-conduct/

Pew Research Center (2020b). A look at the Americans who believe that there is some truth to the conspiracy theory that COVID-19 was planned. July 24, 2020. Retrieved from: https://www.pewresearch.org/fact-tank/2020/07/24/a-look-at-the-americans-who-believethere-is-some-truth-to-the-conspiracy-theory-that-covid-19-was-planned/

Pierre, J. M. (2019). The psychology of guns: Risk, fear, and motivated reasoning. Palgrave Communications, 5(1), 1-7.

Pittman, T. S., \& Zeigler, K. R. (2007). Basic human needs. In A. W. Kruglanski \& E. T. Higgins (Eds.), Social psychology: Handbook of basic principles (p. 473-489). The Guilford Press.

Rokeach, M. (1973). The nature of human values. New York: Free Press.

Salmela, M., \& von Scheve, C. (2017). Emotional roots of right-wing political populism. Social 
Science Information, 56(4), 567-595.

Schofield, N. (2007). The mean voter theorem: Necessary and sufficient conditions for convergent equilibrium. Review of Economic Studies 74, 965-980.

Shepherd, S., Eibach, R. P., \& Kay, A. C. (2017). "One nation under God”: The systemjustifying function of symbolically aligning god and government. Political Psychology, 38(5), 703-720.

Sidanius, J., \& Pratto, F. (2001). Social dominance: An intergroup theory of social hierarchy and oppression. New York: Cambridge University Press.

Slovic, P. (1995). The construction of preference. American Psychologist, 50(5), 364.

Smith, M. B., Bruner, J. S., \& White, R. W. (1956). Opinions and personality. New York: John Wiley \& Sons.

Sniderman, P. M., Brody, R. A., \& Tetlock, P. E. (1991). The role of heuristics in political reasoning: A theory sketch. Reasoning and Choice: Explorations in Political Psychology, 1430.

Sniderman, P. M., \& Bullock, J. (2004). A consistency theory of public opinion and political choice: The hypothesis of menu dependence. Studies in Public Opinion: Attitudes, Nonattitudes, Measurement error, and Change, 337-357.

Thompson, E. P., Roman, R. J., Moskowitz, G. B., Chaiken, S., \& Bargh, J. A. (1994). Accuracy motivation attenuates covert priming: The systematic reprocessing of social information. Journal of Personality and Social Psychology, 66(3), 474-489.

Tomkins, S. S. (1995). Ideology and affect. In E. V. Demos (Ed.), Exploring affect: The selected writings of Silvan S. Tomkins (pp. 109-167). New York: University of Cambridge Press.

Trope, Y. (1979). Uncertainty-reducing properties of achievement tasks. Journal of Personality 
and Social Psychology, 37(9), 1505-1518.

Vincent, A. (2010). Modern political ideologies. New Jersey: Wiley-Blackwell.

Wallas, G. (1908). Human nature in politics. London: Constable.

Weeden, J., \& Kurzban, R. (2016). The hidden agenda of the political mind: How self-interest shapes our opinions and why we won't admit it. Princeton, NJ: Princeton University Press.

White, S. (1986). Economic performance and Communist legitimacy. World Politics: A Quarterly Journal of International Relations, 462-482.

Zajonc, R. (1999). One hundred years of rationality assumptions in social psychology. In Rodrigues, A., \& Levine, R.V. (Eds.), Reflections on 100 Years of Experimental Social Psychology (pp.200-14). New York: Basic Books. 


\section{Appendix}

Derivative of equation (12) $M_{K}^{j}=\widetilde{M}_{K}\left(\left(1-e^{-\frac{1}{p_{K}}\left(Y_{K}-C_{K}\right)}\right)\right)^{\varepsilon_{K}}$

$$
\begin{aligned}
& \frac{d M_{K}^{j}}{d C}=-\frac{\varepsilon_{K}}{p_{K}} \widetilde{M}_{K}\left(1-e^{-\frac{1}{p_{K}}(\bar{Y}-C)}\right)^{\varepsilon_{K}-1} e^{-\frac{1}{p_{K}}(\bar{Y}-C)} \\
& \frac{d^{2} M_{K}^{j}}{d C^{2}}=--\left(1-\varepsilon_{K}\right) \varepsilon_{K} \widetilde{M}_{K}\left(e^{-\frac{1}{p_{K}}(\bar{Y}-C)} \frac{1}{p_{K}}\right)^{2}\left(1-e^{-\frac{1}{p_{K}}(\bar{Y}-C)}\right)^{\varepsilon_{K}-2}(-) \\
& -\varepsilon_{K} \widetilde{M}_{K}\left(1-e^{-\frac{1}{p_{K}}(\bar{Y}-C)}\right)^{\varepsilon_{K}-1} e^{-\frac{1}{p_{K}}(\bar{Y}-C)} \frac{1}{p_{K}} e^{-\frac{1}{p_{K}}(\bar{Y}-C)} \frac{1}{p_{K}} \\
& =-\varepsilon_{K} \widetilde{M}_{K}\left(1-e^{-\frac{1}{p_{K}}(\bar{Y}-C)}\right)^{\varepsilon_{K}-2} e^{-\frac{1}{p_{K}}(\bar{Y}-C) 2}\left(\frac{1}{p_{K}}\right)^{2}\left[2-e^{-\frac{1}{p_{K}}(\bar{Y}-C)}-\varepsilon_{K}\right]<0
\end{aligned}
$$

Determine optimal choice functions $M^{*}, C^{*}$

Optimal choice of ideology: Decision problem:

$$
\begin{aligned}
& \max : U^{j}=\left[\beta_{M}\left(M^{j}\right)^{-\gamma}+\beta_{C}\left(C^{j}\right)^{-\gamma}\right]^{-\frac{1}{\gamma}} \\
& \text { s.t. } C F-\text { curve }: M^{j}=M^{j}\left(\bar{Y}^{j}, C^{j}\right)
\end{aligned}
$$

Taking the enveloping function $M^{j}=M^{j}\left(\bar{Y}^{j}, C^{j}\right)$ (CF-curve) and plugging in directly leads to the maximization problem:

$$
\max _{C}: U^{j}=\left[\beta_{M}\left(M^{j}\left(\bar{Y}^{j}, C^{j}\right)\right)^{-\gamma}+\beta_{C}\left(C^{j}\right)^{-\gamma}\right]^{-\frac{1}{\gamma}}
$$

FOC 


$$
\begin{gathered}
\frac{d U^{j}}{d C^{j}}=-\frac{1}{\gamma}\left[\beta_{M}\left(M^{j}\left(\bar{Y}^{j}, C^{j}\right)\right)^{-\gamma}+\beta_{C}\left(C^{j}\right)^{-\gamma}\right]^{-\frac{1}{\gamma}-1}\left[(-\gamma) \beta_{M}\left(M^{j}\left(\bar{Y}^{j}, C^{j}\right)\right)^{-\gamma-1} \frac{\partial M^{j}\left(\bar{Y}^{j}, C^{j}\right)}{\partial C^{j}}\right. \\
\left.+(-\gamma) \beta_{C}\left(C^{j}\right)^{-\gamma-1}\right]=0 \\
0=F=(-\gamma) \beta_{M}\left(M^{j}\left(\bar{Y}^{j}, C^{j}\right)\right)^{-\gamma-1} \frac{\partial M^{j}\left(\bar{Y}^{j}, C^{j}\right)}{\partial C^{j}}+(-\gamma) \beta_{C}\left(C^{j}\right)^{-\gamma-1}
\end{gathered}
$$

Apply the I.F.Th. : If $\frac{\partial F}{\partial C^{j}} \neq 0 \mathrm{~F}$ implicitly defines a function

$$
C^{j *}=C^{j *}\left(\bar{Y}^{j}, \tau, \beta_{M}, \beta_{C}, \gamma\right)
$$

show $\frac{\partial F}{\partial C^{j}}>0$ :

$$
\begin{aligned}
& (-\gamma-1)(-\gamma) \beta_{M}\left(M^{j}\left(\bar{Y}^{j}, C^{j}\right)\right)^{-\gamma-1-1}\left(\frac{\partial M^{j}\left(\bar{Y}^{j}, C^{j}\right)}{\partial C^{j}}\right)^{2}+(-\gamma-1)(-\gamma) \beta_{C}\left(C^{j}\right)^{-\gamma-1-1}>0 \\
& \beta_{M}\left(M^{j}\left(\bar{Y}^{j}, C^{j}\right)\right)^{-\gamma-2}\left(\frac{\partial M^{j}\left(\bar{Y}^{j}, C^{j}\right)}{\partial C^{j}}\right)^{2}+\beta_{C}\left(C^{j}\right)^{-\gamma-2}>0
\end{aligned}
$$

determine: $\frac{\partial F}{\partial \bar{Y}^{j}}>0$

$$
\begin{gathered}
\frac{\partial F}{\partial \bar{Y}^{j}}=(1+\gamma) \beta_{M}\left(M^{j}\left(\bar{Y}^{j}, C^{j}\right)\right)^{-\gamma-2} \frac{\partial M^{j}\left(\bar{Y}^{j}, C^{j}\right)}{\partial C^{j}} \frac{\partial M^{j}\left(\bar{Y}^{j}, C^{j}\right)}{\partial \bar{Y}^{j}} \\
-\beta_{M}\left(M^{j}\left(\bar{Y}^{j}, C^{j}\right)\right)^{-\gamma-1} \frac{\partial\left(M^{j}\right)^{2}}{\partial C^{j} \partial \bar{Y}^{j}}<0
\end{gathered}
$$

As we can assume that $\frac{\partial\left(M^{j}\right)^{2}}{\partial C^{j} \partial \bar{Y}^{j}}>0$ the derivative $\frac{\partial F}{\partial \bar{Y}^{j}}<0$. Thus an incresing income $\bar{Y}^{j}$ would 
imply an the choice of an ideology that allows for a higher consumption level.

Knowing $C^{j}=C^{j}\left(\bar{Y}^{j}, \tau, \beta_{M}, \beta_{C}, \gamma\right)$ we can also determine via $M^{j}=M^{j}\left(\bar{Y}^{j}, C^{j}\right)$ the respective $M^{j *}$

$$
M^{j *}=M^{j *}\left(\bar{Y}^{j}, \tau, \beta_{M}, \beta_{C}, \gamma\right)
$$

The pair $\left[\boldsymbol{M}^{\boldsymbol{j} *}, \boldsymbol{C}^{\boldsymbol{j} *}\right]$ is a point on the envelop function, and we assume a continuum of ideologies, each point represents one ideology. Thus, $\left[\boldsymbol{M}^{\boldsymbol{j} *}=\boldsymbol{M}_{\boldsymbol{K}}, \boldsymbol{C}^{\boldsymbol{j} *}=\boldsymbol{C}_{\boldsymbol{K}}\right]$ implies a particular ideology $\boldsymbol{K}$ which is chosen when the combination $\left[\boldsymbol{M}^{\boldsymbol{j} *}, \boldsymbol{C}^{\mathbf{j}}\right]$ is chosen. 